\title{
Strengthening of sliding soil body using gravitational pile structure at highway in Chita Region
}

\author{
Tatiana Valtseva ${ }^{1, *}$, Sergey Kudryavtsev ${ }^{1}$, Elena Goncharova ${ }^{1}$, and Anastasiya Peters ${ }^{1}$ \\ ${ }^{1}$ Far Eastern State Transport University, 47 Seryshev St. Khabarovsk, 680021, Russia
}

\begin{abstract}
This article presents the way to prevent deformation of linear structures build on sliding slopes. The offered structure is built on thawing permafrost soils. Some results of scientific research and engineering calculations of options for rational design of roads located in cold regions of Russia are given as an example of a highway construction. The highway is constructed in complicated climatic and engineering-geological conditions. There are occurrences of insular permafrost and a wide spread of deep seasonal freezing. Melting permafrost requires special treatment in construction due to changing their temperature and humidity conditions. Thus, the structure includes installation of piles in slopes and their interconnection in a pilework by means of a vertical geogrid rigidly connected to pile caps and vertical geogrid layers. The work stage from cap bottoms to the first layer of a horizontal geogrid and interlayers between geogrids are filled with the crushed stone compacted. The horizontal geogrids are installed on account of their partial location in a no-float soil body of the slope or natural downhill. Modelling of the structural behavior with the geotechnical software complex «FEM models» estimates the gravitational effect of a sliding body of earth. The reliability of the structure is confirmed by regular measurements and observations on the highway section. On the basis of the research results some structural measures for providing operational reliability for highway rational designs in the northern territories of the Russian Far East are offered.
\end{abstract}

\section{Introduction}

Project construction in the Russian Far East, the Chita Region and Yakutia is always connected with frost and seasonally freezing soil risks [1-4]. It is especially true for the linear transport projects that require high reliability and responsibility standards. The structures must provide the admissible deformability and bearing capacity of foundations for the perspective rolling load in complex geological and natural climatic conditions [5].

The complexity of the highway project in the Chita Region is connected with permafrost in the base and its thaw-freeze due to changing the temperature and humidity conditions, thus requiring some special treatment in the project construction $[6,7]$.

\footnotetext{
* Corresponding author: olgacudr56@ mail.ru
} 
The designed earth gravitational pilework with the geosynthetical material grill and the crushed stone fill is offered as one of the measures for stabilization of deformations in the base body of the current automobile road experiencing gravitational slope processes [8-10].

The designed structure serves for a compensation of the horizontal and tangential components from the gravitational impact of the sliding body of earth on the given section of terrain. Though it is considered a passive measure alongside with the active ones, such as the interception ditch construction with a complete isolation of the surface water and the permafrost insulation from its degradation, the structure is an integral part of the complex measures in the stabilization period for providing the operational reliability of the whole construction and the traffic safety on the deformed section until the active measures work in full (Fig.1, 2).

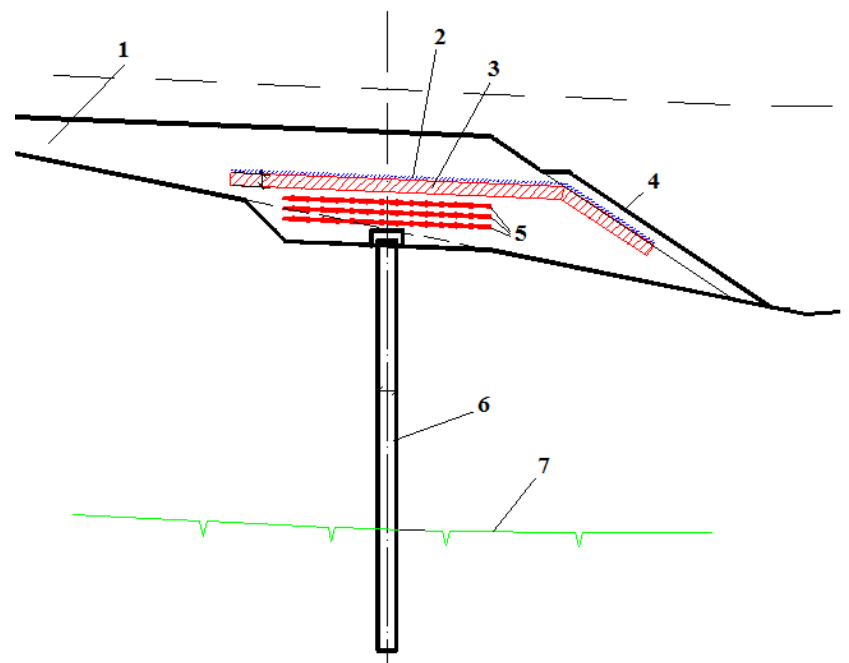

Fig. 1. Retaining pile-an-earth gravitational structure: 1 - clay soil and crushed stone fill; 2 geotextile; 3 - foam polystyrene; 4 - protective powdering; 5 - two-axis geogrid E'GRID 3030; 6 pile $0.35 \mathrm{x} 0.35 \mathrm{~m} ; 7$ - permafrost linesection of embankment with element of variable stiffness; axis on picket $137+50$.

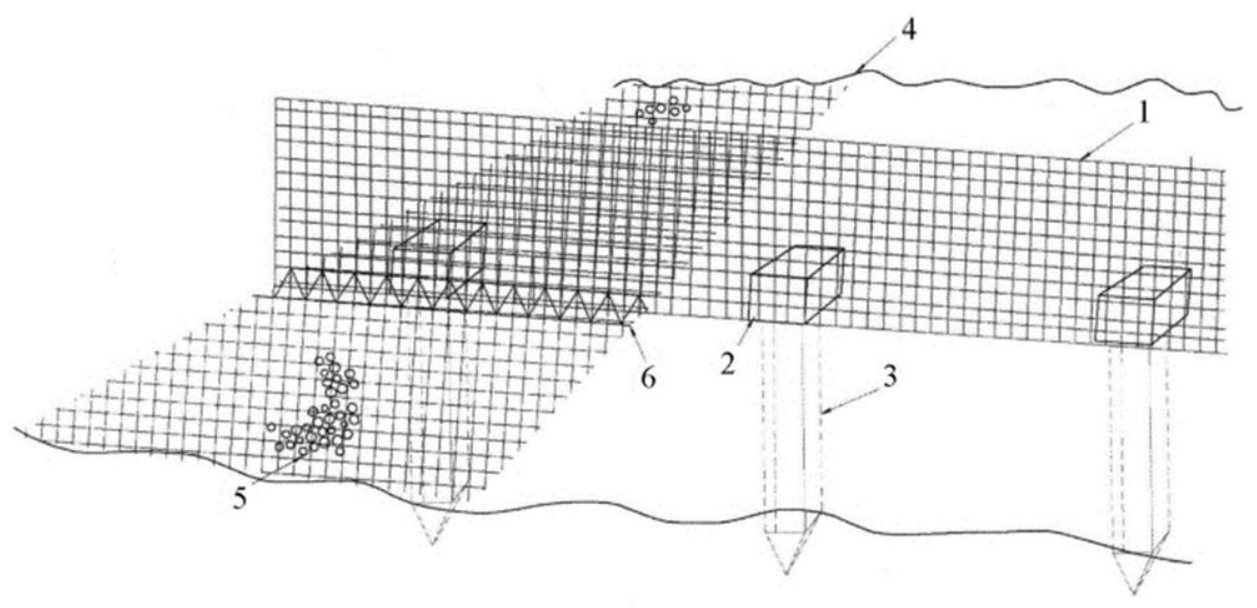

Fig. 2. Restraining pile-an-earth gravitational structure: 1 - vertical geogrid; 2 - pile cap; 3 - pile; 4 horizontal geogrid; 5 - crushed stone; 6 - twist joint. 
As The offered structure allows:

- exclude deformations of linear structures constructed on sliding downhills or slopes in the conditions of changing temperature and humidity in soils;

- avoid hydrodynamic pressure created by a seepage flow on the pile protection, thus excluding its thermal impact on the permafrost located in slopes;

- raise the pile structure effectiveness in the conditions of a local permafrost degradation on account of possible changes in ratio of vertical and horizontal geogrids as far as their geometry and arrangement;

- change essentially the stress-strain behaviour of the slope for increasing its stability;

- minimize the risk of deformation occurrences in the linear structures constructed on sliding downhills or slopes in the conditions of changing temperature and humidity in soils;

- decrease the cost of the landslide control;

- increase the effectiveness of the linear structure protection from local landslide occurrences.

\section{Methods of numerical modeling}

As discussed in the works [11-15], it is necessary to perform a calculation.

The design geotechnical modeling was performed using software package «FEM models», which was developed by geotechnical engineers from Saint-Petersburg.

The elastic-plastic model with the yield criterion was used to describe the work of variable stiffness design. This elastic-plastic model was chosen because its parameters can be taken from existing material of engineering and geological surveys.

Numerical methods are in good correspondence with the traditional engineering methods of calculating the settlement in such formulation. They provide accurate description of deformations in structures.

Figure 3 shows a scheme of determining the theoretical stresses in the elastic-plastic model of the soil.

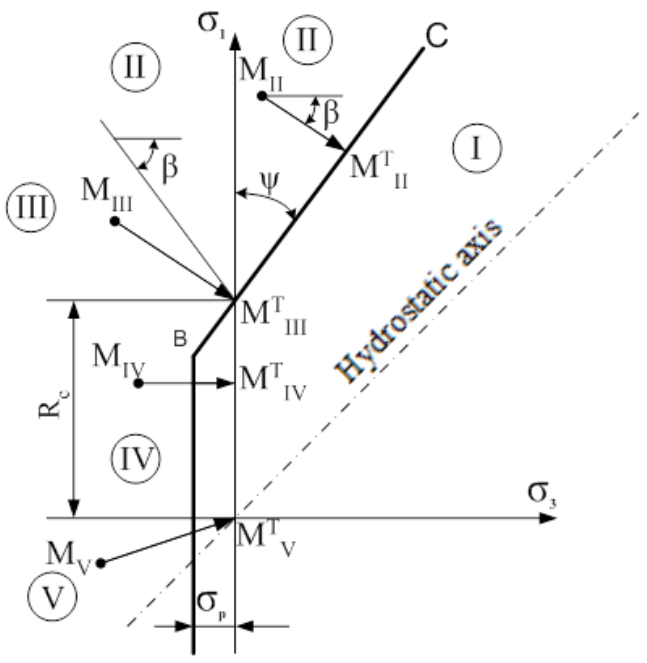

Fig. 3. Scheme of determining theoretical stresses in elastic-plastic model of soil.

If the point $\mathrm{M}$ occurs beyond the yield behavior contour, the theoretical stresses are calc The ultimate stresses in the tension field are restricted by the tensile strength $\sigma p$.

Area I in the tension field is restricted by the stress $\sigma 3=\sigma p$, while in the compression area it is restricted by the Coulomb strength criterion according to: 


$$
\sigma_{1}=R_{c}+\sigma_{3} \operatorname{ctg} \psi
$$

where $\mathrm{Rc}$ is the uniaxial compression strength.

The element stiffness matrixes and the ones for the whole system are formed once and stay the same in the procedure of elastic-plastic solution. The load is applied in small portions as it happens in its real sequence in nature.

If the point $\mathrm{M}$ occurs within the limits of the elastic region I, it means the element is in the elastic state and there is no need to correct the stresses.

ulated in the following order. If the point of total stress occurs in the area II (the basic plastic zone), the theoretical point lies at the intersection of the plastic yield and the right line.

If the point of total strength occurs in area III, the element breaks in the direction of the stress, while the stresses go down to the level of the soil strength to the uniaxial compression.

For the area IV where the stresses do not go beyond the uniaxial compression strength, the parameters are the following. Finally, for the area $\mathrm{V}$ where the element is broken, the parameters are the following:

In the FEM Models program the natural stress state is substituted by the hydro engineering tensor for pressing the soil of the "characteristic volume" that is summarized with the actual stresses in situ:

$$
\left\{\sigma_{1,3}\right\}=\left\{\sigma_{1}^{F}, 3\right\}+\left\{\sigma_{1}^{G}, 3\right\}
$$

The assumption reflects a real picture of the natural stress state in weak soils.

The used method and the software package «FEM models» are developed by the authors for the projects under construction in Russia and the Far East.

Application of the methods and approaches for the calculation and design of geotechnical structures using software package «FEM models» show its accurate and objective performance in the most rational calculations of geotechnical constructions. This can be seen from the works [16-19].

\section{Results of numerical simulation}

On The geotechnical modelling of the landslide body is carried out by the finite element method FEM models. The received picture of elastic deformation zones and dangerous areas of plastic deformations is close to real. Fig. 4 shows the structural design of the elastic and plastic deformations on the highway in the Chita Region.

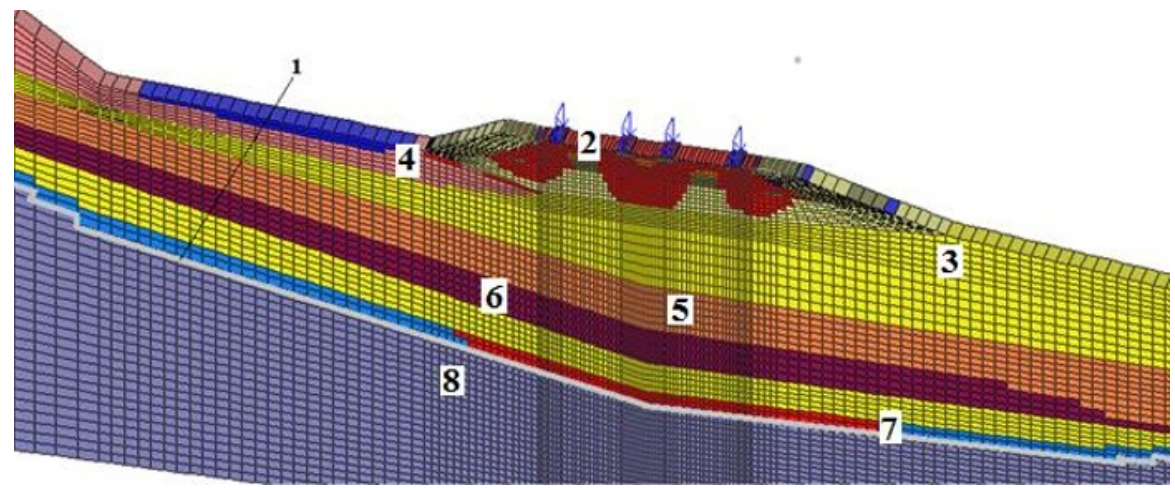

Fig. 4. Zones of elastic (blue colour) and plastic (red colour) deformations: 1 - slip surface; 2 pavement; 3 - clay loam, light, hard; 4 - gravel sand, slightly wet; 5 - clay loam, light, hard plastic with layers of slightly wet sand; 6 - clay loam, hard; 7 - layer of thaw permafrost; 8 - permafrost. 
The results show that the slip surface is located in the layer of thaw overmoistured clay loam soils of a little thickness located above the top line of permafrost causing the soil body movement [16,17].

The zones under consideration of plastic deformations are located in the layer of a frozen soil thawed to high-plastic and extremely high liquid limit soil consistency. This signifies that the whole soil body is a subject to sliding in the given layer. Besides, the horizontal deformation analysis confirms a progressive slipout of the structure along the thaw soil layer $[18,19]$.

The geotechnical modelling results of the behaviour of the structure with the design elements on the Amur highway section Chita-Khabarovsk to the settlement Peschanka, the Chita Region, are shown in Fig. 5, 6

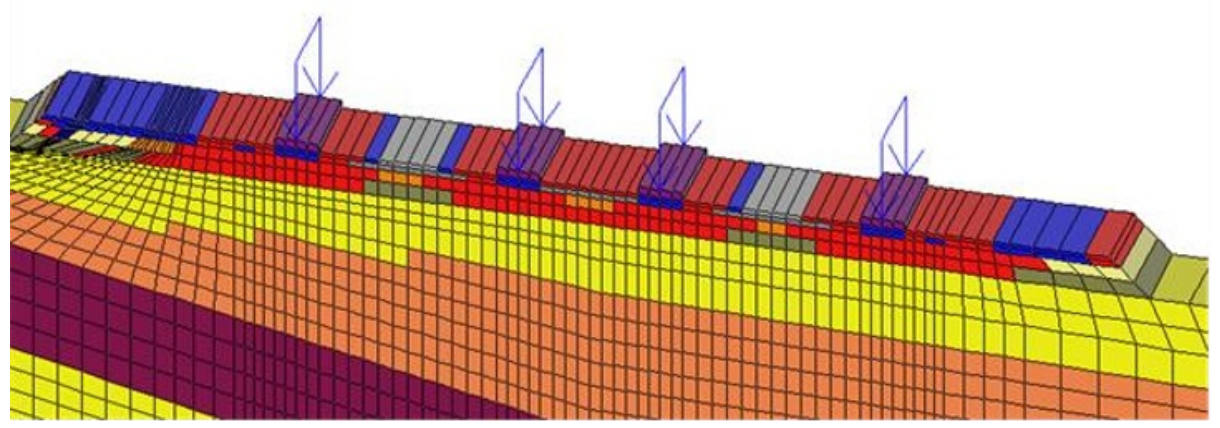

Fig. 5. Zones of elastic (blue colour) and plastic (red colour) deformations.

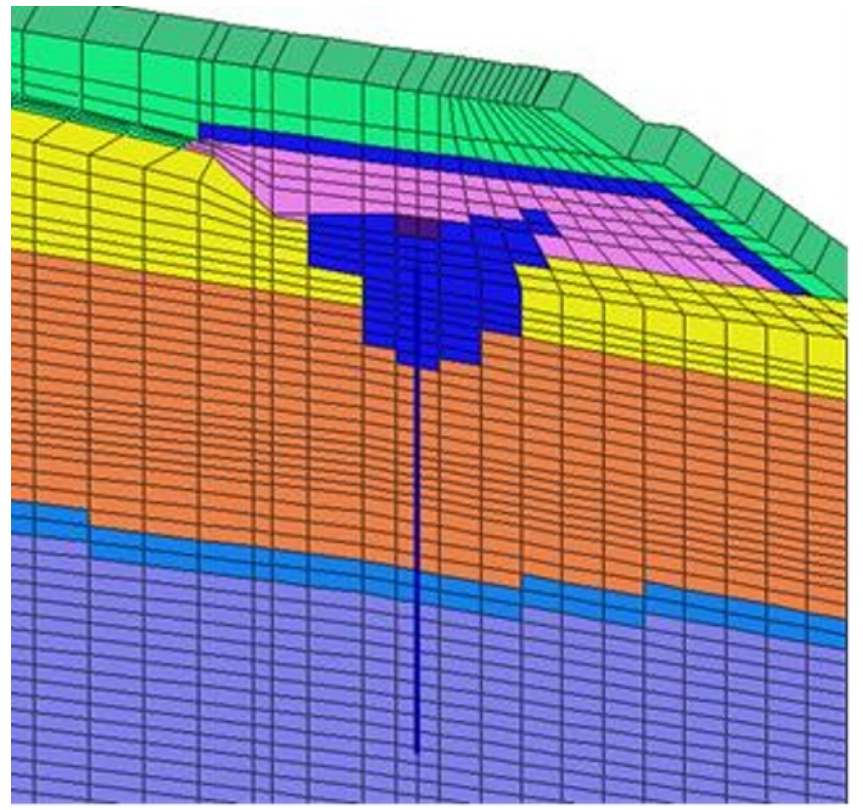

Fig. 6. Zones of elastic deformations in retaining pile-an-earth gravitational structure: blue colour elastic deformations, red colour - plastic deformations. 


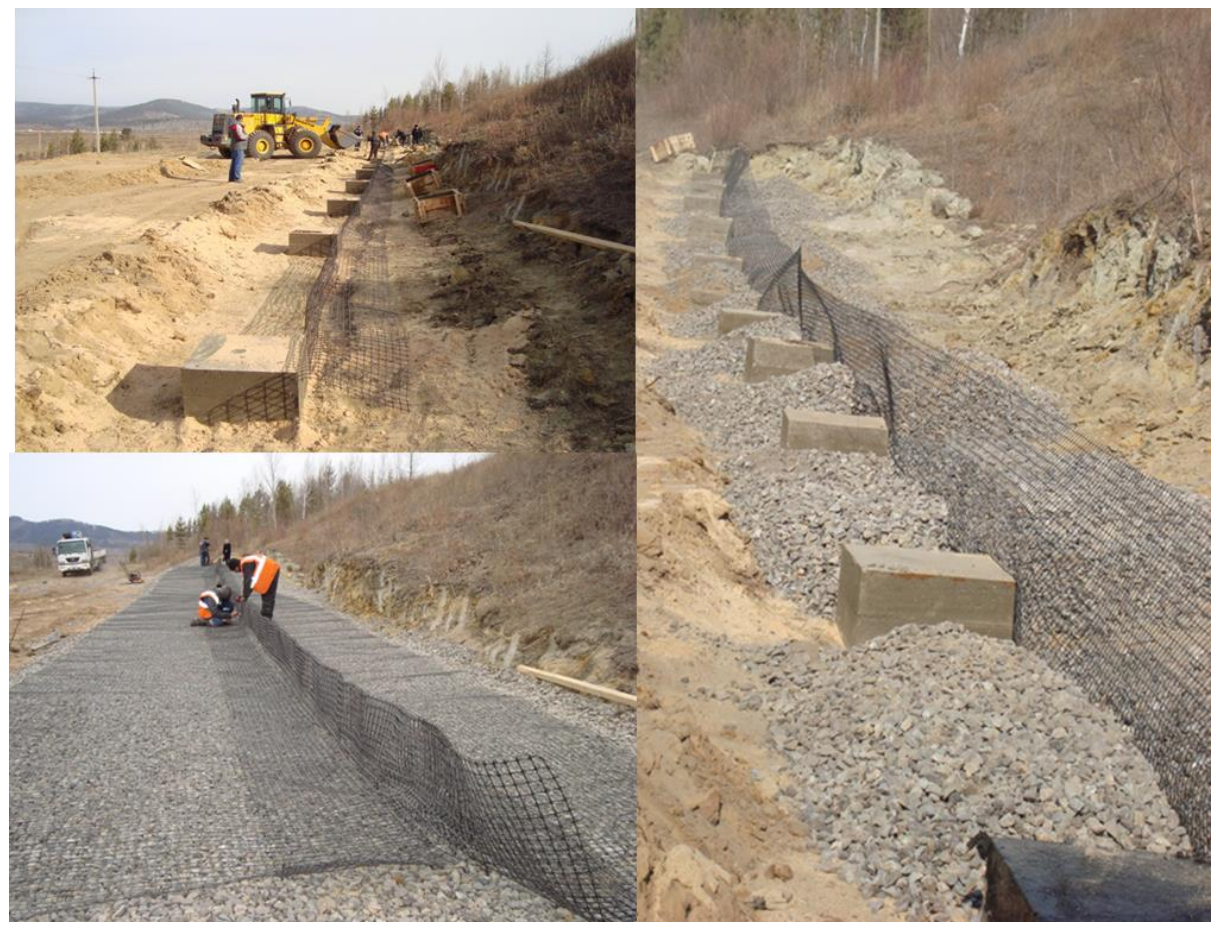

Fig. 7. Pile caps installation, crushed stone filling, geogrid fastening with binding.

\section{Conclusions}

1. The geotechnical modeling results show the decrease of overall non-reversible deformations in the structure.

2. In the area of the retaining pile-an-earth gravitational structure only elastic deformations occur that excludes the road embankment shifts.

3. Overall horizontal and vertical shifts of the road embankment with the retaining pile-anearth gravitational structure is decreased by $25 \%$ for different parts in general.

4. The road embankment with the design solutions provides ample stability.

5 . The ample stability is proved by regular surveys, geodesic research with special equipment and marks, measurements and observations of the slope top during the period of 2013-2017. 6. Using modern geotechnologies and new geosynthetic materials in construction has a progressive tendency. They are a reliable alternative in many ways to the traditional solutions and are more economically effective.

\section{References}

1. Y. Berestyanyy, T. Valtseva, S. Kudryavtcev, E. Fedorenko, Innovations in construction 29, 96-100 (2013)

2. Y. Berestyanyy, T. Valtseva, S. Kudryavtcev, R. Mikhailin, II International Symposium "Physics, chemistry and snow mechanics", Yuzhno-Sakhalinsk, 96-100 (2013)

3. Y. Berestyanyy, E. Goncharova, S. Kudryavtcev, R. Mikhailin, T. Valtseva, The 24rd International Off-shore (Ocean) and Polar Engineering Conference, 502-506 (2014) 
4. T. Valtseva, E. Goncharova, S. Kudryavtcev, R. Mikhailin, The 6th International geotechnical symposium on Disasters Mitigation in Special Geoenvironmental Conditions, Indian Institute of Technology, 409-412 (2015)

5. Y. Berestyanyy, T. Valtseva, S. Kudryavtcev, Proceedings of the 44th All-national scientific conference "Modern technologies to railway transport and industry" 1, 24-27 (2006)

6. Y. Berestyanyy, S. Kudryavtcev, T. Valtseva, N. Barsukova, The 1st International conference on new developments in geoenvironmental and geotechnical engineering, 423-427 (2006)

7. Y. Berestyanyy, S. Kudryavtcev, T. Valtseva, V. Chylichkov, D. Tsvigunov, 8th International Symposium on Cold Region Development. ISCORD 2007, $37-38$ (2007)

8. Y. Berestyanyy, S. Kudryavtcev, T. Valtseva, Geotechnical Engineering, Ground Improvement and Geosynthetics for Human Security and Environmental Preservation, 493-500 (2007)

9. Y. Berestyanyy, S. Kudryavtcev, T. Valtseva, R. Mikhailin, The 4th international scientific conference, Modern problems of projecting, construction and railway road exploitation, 116-121 (2007)

10. Y. Berestyanyy, S. Kudryavtcev, T. Valtseva, Conditions and perspectives of permafrost engineering, 113-116 (2008)

11. Y. Berestyanyy, S. Kudryavtcev, E. Fedorenko, T. Valtseva, R. Mikhailin, Proceedings of the Russian National and Int.l Conf.e on scientific and technical cooperation of APRcountries in XXI century 2, 24-27 (2009)

12. Y. Berestyanyy, S. Kudryavtcev, E. Fedorenko, T. Valtseva, R. Mikhailin, 3rd Int. Geotechnical Symposium on Geotechnical Engineering for Disaster Prevention and Reduction, Harbin Institute of Technology, 18-25 (2009)

13. Y. Berestyanyy, E. Goncharova, S. Kudryavtcev, R. Mikhailin, T. Valtseva, 14th Conference on cold regions engineering, 45-48 (2009)

14. Y. Berestyanyy, S. Kudryavtcev, E. Fedorenko, T. Valtseva, E. Goncharova, R. Mikhailin, Materials of the IX International Symposium on Cold Regions Development, Yakutsk (2010)

15. Y. Berestyanyy, S. Kudryavtcev, E. Fedorenko, T. Valtseva, R. Mikhailin, Proceedings of the second regional scientific conference on problems of railroad and motorway embankment in Siberia, 37-47 (2011)

16. Y. Berestyanyy, T. Valtseva, R. Mikhailin, Track and its facilities 6, 34-35 (2011)

17. Y. Berestyanyy, S. Kudryavtcev, E. Fedorenko, T. Valtseva, E. Goncharova, R. Mikhailin, International Symposium on Geosynthetics Technology, 117-125 (2011)

18. Y. Berestyanyy, S. Kudryavtcev, T. Valtseva, E. Goncharova, R. Mikhailin, The 24rd International Offshore (Ocean) and Polar Engineering Conference, 502-506 (2014)

19. S. Kudryavtcev, A. Kazharsky, E. Goncharova, T. Valtseva, Zh. Kotenko, Procedia Engineering 165, 1080-1086 (2016) 